\title{
The Influence of Climatic Conditions on The Vegetative Development of Vine Varieties Grapes Grown inThe Wine-Growing Center - Copou Iași
}

\author{
Lulu Cătălin ALEXANDRU ${ }^{1)}$, Liliana ROTARU ${ }^{1 *}$, Doina DAMIAN ${ }^{2)}$, Ancuţa NECHITA ${ }^{2)}$ \\ ${ }^{1)}$ Faculty of Horticulture, University of Agricultural Sciences and Veterinary Medicine "Ion Ionescu de la \\ Brad" Iaşi, Romania. \\ ${ }^{2}$ Research - Development Station for Viticulture and Vinification of Iaşi, Romania. \\ ${ }^{*}$ Coresponding author, e-mail: lirotaru@uaiasi.ro
}

Bulletin UASVM Horticulture 71(2) / 2014

Print ISSN 1843-5254, Electronic ISSN 1843-5394

DOI:10.15835/buasvmcn-hort:10297

\begin{abstract}
Environmental factors in a vineyard ecosystem form a complex of factors which are interdependent and can restrict, hinder or stimulate the growth and development of the vine. The singular or cumulative effects of climatic risks and identification of most vulnerable areas are basic criteria in elaborating and founding a decisional system for long term agro-climatic management. In the last years, the changes of the environmental factors have become more and more visible. The repercussions are registered in the vineyard system as well; the grape varieties alter their annual life cycle. In the northern area of Romania, an increase of the thermal regime and a decrease of rains led to a thermic and hydric stress of plants. The climatic changes of the last years, more or less at random, can seriously harm the homogeneity of viticultural biocenotic conditions, with unpredictable implications on the quantity and quality of the grape harvest. This study aims to contribute scientific and practical on how the climatic factors in the years 2012/2013, as atypical, influenced vegetative growth and further development of grapevines varieties 'Gelu' and 'Paula' compared with 'Aromat de Iași'.
\end{abstract}

Keywords: grapevine varieties, 'Gelu', 'Paula', vegetative development, Vitis vinifera $L$.

\section{INTRODUCTION}

The level of the climatic factors in a winegrowing ecosystem influences the biological and metabolic processes conditioning the growth and development of the vine and implicitly the production and its quality and its response to biotic and abiotic factors (Haras and Rotaru 2012).

The global heating caused a disturbance in the evolution of natural factors of the vineyard ecosystem: summers became extremely dry, autumns became either colder or wetter, either much warmer than usual, while winters are shorter and with extreme low temperatures. It became very usual to record frequent alternations of dry spells with excessive wet periods (Becker et al., 1992).

The consequences for vineyards are as follows: because of the prolonged active period of vegetation, the vines enter unprepared and not matured enough in winter. The atypical autumn climatic conditions lead to a defective maturation of the grapes which, therefore have small quantities of natural components, responsible for wine quality (Vaudour, 2003).

The singular or cumulative effect of the restrictive climatic factors for the crop of table grape varieties and the identification of the most vulnerable areas are basic criteria in elaborating 
and creating a long-term decisional agro-climatic management system (Colibaba et al., 2013).

During the past years, the global climatic changes are almost as intense in Romania, including the wine-growing ecosystem of Iaşi. These changes regard especially the level of the average, maximum and minimum temperatures, and their increase, as well as a visible decrease in the precipitation amount, with repercussions on the evolution of the annual cycle of the winegrowing variety, and their cumulative effect can generate a thermal and hydric stress (Rotaru and Colibaba, 2013).

The ecological states of wine environment now have a negative tendency increased with the total climatic changes. By time, all the probable climatic changes will have repercussions in the vineyards and on the durability of the wine plantations. The climatic factors in general do not act separately, but as a complex of factors that condition each other, influencing the growth and development of the vine in tight congruence with its biological particularities (Reynier, 2000). The diminishment of the vegetative growth of the varieties leads to the diminishment of the quantitative and qualitative production of the same, and respectively to considerable damage.

\section{MATERIALS AND METHODS}

The studied materials has been the new varieties of table grapes 'Paula' and 'Gelu', created in the Station of Research and Development for Winegrowing and Wine Production of Iaşi, which are compared to another new variety - 'Aromat de Iaşi'.

The experimental plantations are located on a black earth plateau of south-eastern exposure, where the planting distances are $2.2 \mathrm{~m} / 1.2 \mathrm{~m}$, ensuring a density of 3,787 stocks/ha. The used crop system was on $70-80 \mathrm{~cm}$ high stems, the stocks being short pruned to the bilateral cordon, with 2-3 spur rods, ensuring the fruitage of 3540 buds per stock, and base safety rods for the protection of the stock base during the winter.

In view of establishing the influence of the climatic factors from 2012 and 2013 on the vegetative development of the studied varieties, the researches focused on the following elements: the monitoring of the climatic factors by AGROEXPERT weather station, and the calculation of the following ecoclimatic indexes: useful thermal balance (UTB), active thermal balance (ATB), annual average temperature (aT), absolute maximum temperature, absolute minimum temperature, actual heliothermal index (Ahi), hydrothermal coefficient (HC), vine bioclimatic index (Vbi), wine-climatic capability index, annual and multi-annual wood amount removed by winter pruning, on repetitions of 50 stocks/ repetition each study year, and the statistical mathematical interpretation of the outcomes. Furthermore, in order to illustrate the balance between the growth vigour and the grape production, certain vegetative-productive indexes and the Ravaz index (1903), cited by Damian et al (1995) have been determined by relating the production to the annual wood amount removed by pruning ( $\mathrm{kg} / \mathrm{stock}$ ), and the vegetal-productive balance index (VPBI), elaborated by Maccarone and Scienza (1996) and then by Belea (2008), as the ration between the wood weight $\mathrm{x} 100$ and the grape production + the removed wood, and whose optimum ranges are between 4 and 8 for the first case and between 2 and 12 for the second.

\section{RESULTS AND DISCUSSIONS}

The climatic monitoring of Copou vineyard ecosystem of Iaşi during the study years 2012 and 2013 highlights the presence of climatic stress factors that influenced the biological processes of the studied varieties.

Their analysis and the comparison to the multiannual values reveals an increase in the annual average temperature by $0.7{ }^{\circ} \mathrm{C}$ in 2012 $\left(10.4{ }^{\circ} \mathrm{C}\right.$,) and $0.6{ }^{\circ} \mathrm{C}$ in $2013\left(10.3^{\circ} \mathrm{C}\right)$ (Tab.1). The active and useful thermal balances had the same tendency, in 2012 the sum of the active temperature degrees $\left(3,596{ }^{\circ} \mathrm{C}\right)$ exceeding by over $500{ }^{\circ} \mathrm{C}$ the multiannual average value $\left(3,009.6{ }^{\circ} \mathrm{C}\right)$ calculated for 40 years, and by $137{ }^{\circ} \mathrm{C}$ the useful ones. The values of the absolute maximum temperature were under the multiannual value of $42.3{ }^{\circ} \mathrm{C}$, but very close to it in $2012\left(40.1^{\circ} \mathrm{C}\right)$. That same year, the absolute minimum temperature $\left(-26.7^{\circ} \mathrm{C}\right)$ was close to the multiannual one, leading to important losses of viable buds with implications on the growth and development of the vegetative system and the grape production.

The reported amount of precipitations reveals that 2012 was a very draughty year, with only $287.2 \mathrm{~mm}$ precipitations during the vegetation period, much under the normal value of 403.0 
Tab. 1. Values of the main climatic factors from the vineyard ecosystem of Iaşi, in the vegetation period of the years $2012-2013$

\begin{tabular}{lccc}
\hline Studied climatic elements & Year 2012 & Year 2013 & $\begin{array}{c}\text { Multiannual } \\
\text { average }\end{array}$ \\
\hline Annual average temperature $\mathrm{T}^{\circ} \mathrm{C}$ & 10.4 & 10.3 & 9.7 \\
\hline Absolute maximum temperature ${ }^{\circ} \mathrm{C}$ & 40.1 & 33.7 & 42.3 \\
\hline Absolute minimum temperature ${ }^{\circ} \mathrm{C}$ & -26.7 & -14.3 & -27 \\
\hline Active thermal balance, $\left.\Sigma \mathrm{t}^{\circ} \mathrm{a}\right)$ & $3,596.3$ & $3,147.1$ & $3,009.6$ \\
\hline Useful thermal balance, $\left(\Sigma \mathrm{t}^{\circ} \mathrm{u}\right)$ & $1,856.3$ & $1,467.1$ & $1,359.7$ \\
\hline $\begin{array}{l}\Sigma \text { of precipitations from the vegetation } \\
\text { period, mm }\end{array}$ & 287.2 & 501.1 & 403.0 \\
\hline Relative air humidity, $\%$ & 57.0 & 66.0 & 63.0 \\
\hline $\begin{array}{l}\Sigma \text { of the hours of insolation from the } \\
\text { vegetation periods, hours }\end{array}$ & $1,499.1$ & $1,426.1$ & $1,448.0$ \\
\hline Actual heliothermal index & 2.8 & 2.1 & 1.96 \\
\hline Hydrothermal coefficient & 0.8 & 1.6 & 1.34 \\
\hline Bioclimatic index & 10.7 & 5.4 & 7.08 \\
\hline Wine-climatic index & $5,058.2$ & $4,322.1$ & $4,106.1$ \\
\hline
\end{tabular}

$\mathrm{mm}$, and 2013 was a rather rainy year, with 501.1 $\mathrm{mm}$ of precipitations. The relative air humidity of $57 \%$ was under the multiannual average of $63 \%$ in 2012, and over this value in 2013 (66\%).

The combined effect of the reminded climatic factors was expressed by means of synthetic indicators that include the action of two or three climatic factors and whose values serve in characterising the climatic potential of a vineyard or winegrowing centre. Thus, the analysis of the value of the actual heliothermal index (aHi) reveals that in 2012 its value of 2.8 (between 1.75 and 2.25 in Moldavia) exceeded by much the multiannual average (1.96), indicating a very warm year, rich in heliothermal resources. The heliothermal coefficient (HC) had different values in the 2 years, giving a character close to the semidesert to year 2012 and a very humid character to year 2013.

The values of the ternary eco-climatic index, the winegrowing bioclimatic index (Wbi) and the wine-climatic capability index (WCCI) indicate the same characteristics of the ecosystem, namely a hot and draughty 2012 and a thermally normal and rather humid 2013.

The growth vigour of the stocks of the table grape varieties, estimated based on the wood amount removed upon pruning was conditioned by the level of climatic factors, by the fruitage left upon pruning as well as the hereditary specificity of each variety. Hence, in the same ecoclimatic and agro-technical conditions, the biometrical determinations done related to the wood removed upon pruning in 2013 and 2014 for the vegetative growth in 2012 and 2013 show different values from one year to the other, as well as from one genotype to another.

In Paula variety, with a medium to high vigour, the annual wood amount removed upon the fruiting pruning in 2013 was of $0.408 \mathrm{~kg} /$ stock, and $1.545 \mathrm{~kg} / \mathrm{ha}$ respectively, the multiannual wood amount removed was $0.23 \mathrm{~kg} /$ stock and 882 $\mathrm{kg} / \mathrm{ha}$ respectively, which are values higher than the ones of the control variety - Aromat de Iaşi which is a medium vigour variety more resistant to frost (Tab. 2).

The vigour increment of Paula variety was significantly ensured from the statistical point of view. Gelu variety has also high growth vigour, in which the wood amount removed by pruning in the spring of 2013 was $0.327 \mathrm{~kg} /$ stock, and 1493 $\mathrm{kg} / \mathrm{ha}$ respectively.

These values place this variety under Paula variety and the control variety - Aromat de Iaşi from the point of view of the growth vigour. They mirror the fact that the varieties were affected by the very low temperatures from the winter of 2012, when the bud losses were considerable, the number of sprouts per stock was lower, and the hot weather and the lack of precipitations from 
the vegetation period obviously diminished the growth vigour of the stocks. This is also reflected in the multiannual wood amount removed upon the fruiting pruning, which was higher in Paula variety $(0.23 \mathrm{~kg} / \mathrm{stock})$, followed by Gelu variety with $0.14 \mathrm{~kg} / \mathrm{stock}$, which are values higher than the ones of the control variety - Aromat de Iaşi 0.18 $\mathrm{kg} / \mathrm{stock}$ ). All these values prove that the level of precipitations in 2012 had a negative influence on the vegetative development from 2013 of the studied varieties, limiting the vegetative growth and implicitly their growth vigour.

The results obtained in 2013, which was considered almost normal from the point of view of the values of climatic factors reveal that the table grape varieties Paula and Gelu had vegetative growth specific to each of them. Thus, upon the fruiting pruning from the spring of 2014, the annual wood amount removed was double in both varieties, and in the control variety (Tab. 3).

It was revealed through normal vegetative growth corresponding to the hereditary specificity of Gelu variety, in which $0.744 \mathrm{~kg} /$ stock, and 2.817 $\mathrm{kg} / \mathrm{ha}$ respectively, of annual wood was removed by pruning, which are values higher than in Paula variety, which is a medium vigour variety, with $0.683 \mathrm{~kg} /$ stock annual wood removed, and higher than in variety control Aromat de Iași with 0.651 $\mathrm{kg} /$ stock. The vegetative growth differences of Gelu variety from the control variety are quite significant from the mathematical statistical point of view. As regards the multiannual wood amount removed, it was much lower than the previous year, due to the favourable climatic conditions in winter and during the vegetation period in 2013, and no stem or dry cordon etc. removing interventions were necessary. In conclusion, the results obtained from the researches carried out regarding the influence of the climatic factors on the vegetative development of the table grape varieties under study support the results obtained until now by other studies on climatic factors (Damian et al., 1995, 2013; Donici et al., 2013) together with the genetic features of the variety influence the main physiological and biological processes conditioning the growth, development and production of grape as well as its quality.

Tab. 2. Wood amount removed by pruning in the 2012/2013 winter

\begin{tabular}{lcccc}
\hline \multirow{2}{*}{ Variety } & \multicolumn{2}{c}{ Annual wood removed } & \multicolumn{2}{c}{ Multiannual wood removed } \\
\cline { 2 - 5 } & $\mathrm{kg} /$ stock & $\mathrm{kg} / \mathrm{ha}$ & $\mathrm{kg} / \mathrm{stock}$ & $\mathrm{kg} / \mathrm{ha}$ \\
\hline 'Gelu' & 0.327 & 1,235 & 0.14 & 530 \\
\hline 'Paula' & 0.408 & $1,545^{*}$ & 0.23 & 882 \\
\hline 'Aromat de Iași' (cv) & 0.340 & 1,285 & 0.18 & 682 \\
\hline
\end{tabular}

LSD $5 \%=2.82$

LSD $1 \%=4.303$

LSD $0.1 \%=6.913$

Tab. 3. Wood amount removed upon pruning in the 2013/2014 winter

\begin{tabular}{lcccc}
\hline \multirow{2}{*}{ Variety } & \multicolumn{2}{c}{ Annual wood removed } & \multicolumn{2}{c}{ Multiannual wood removed } \\
\cline { 2 - 5 } & $\mathrm{kg} /$ stock & $\mathrm{kg} / \mathrm{ha}$ & $\mathrm{kg} / \mathrm{stock}$ & $\mathrm{kg} / \mathrm{ha}$ \\
\hline 'Gelu' & 0.744 & $2,817^{* *}$ & 0.038 & 144 \\
\hline 'Paula' & 0.683 & 2,586 & 0.0 & 0.0 \\
\hline 'Aromat de Iași' (cv) & 0.651 & 2,465 & 0.02 & 76 \\
\hline
\end{tabular}

LSD $5 \%=2.22$

LSD $1 \%=3.37$

LSD $0,1 \%=5.42$ 
Tab. 4. Vegetative-productive indexes

\begin{tabular}{lcccccc}
\hline \multirow{2}{*}{ Variety } & \multicolumn{3}{c}{ Ravaz's index } & \multicolumn{3}{c}{ Vegetative-productive balance index } \\
\cline { 2 - 7 } & 2012 & 2013 & Average & 2012 & 2013 & Average \\
\hline 'Gelu' & 6.1 & 6.68 & 6.39 & 14.09 & 20.2 & 17.15 \\
\hline 'Paula' & 4.28 & 9.51 & 6.89 & 55.81 & 15.382 & 35.59 \\
\hline 'Aromat de Iași' (cv) & 5.02 & 6.91 & 5.96 & 58.52 & 22.18 & 40.35 \\
\hline
\end{tabular}

The climatic conditions from the two years of the research allowed investigations regarding the contribution of the vegetative part in the grape production. On this line, certain indexes expressing the balance between the growth and fructification processes, namely: Ravaz's index expressing best the ration between growth and fructification and the vegetative-productive balance index, whose values provide information on the influence of certain agro-technical measures (fruitage) on the grape production (Tab. 4).

The analysis of the Ravaz index, whose optimum values are between 4 and 8 revealed that in 2012 there was an optimum balance between growth and fructification in all studied varieties. In comparison to 2012, in 2013 the Ravaz index values were within the optimum range in Gelu variety (6.68), the maximum value being in Paula variety - 9.51 - whose vegetative development places this variety in the category of low value varieties.

In 2012 Gelu variety had an optimum ratio between the fruitage and fructification (14.09), while in Paula variety and the control variety the ratio was very high, indicating that the fruitage was higher, acting to the detriment of the grape production.

The readjustment of the vegetative potential of the varieties by means of appropriate agrotechnical measures, as well as the favourable climatic factors during the vegetation period of the following year led to an optimum balance between the cultural measures and production, both varieties falling into the optimum range of this index, the control variety Aromat de Iaşi having a slightly higher value, where the fruitage has a negative influence on the grape production.

The results obtained in this experiment done in two years under different climatic conditions highlight that a vegetative-productive balance of the studied varieties was influenced to a large extent by the climatic conditions.

\section{CONCLUSIONS}

The wine-growing year 2012 was unfavourable for the processes of growth, vegetative development and fructification, for vine growing in the north-eastern area of the country.

The table grape varieties Paula and Gelu reacted differently under the cumulative action of the climatic factors and the agro-technical measures applied, having vegetative growth under the biological potential from the climatically normal years.

The annual and multiannual wood amount removed upon pruning reveals vegetative growth lower than in 2012, with values between 0.327 $\mathrm{kg} /$ stock (Gelu) and $0.408 \mathrm{~kg} /$ stock (Paula), and double amounts in 2013.

The biological balance between the growth and fructification fell into the optimum range in both studied years, except Paula variety, which, due to the Ravaz index value from 2013, belongs to the low value category.

In 2012, the values of the vegetativeproductive index were favourable for productions corresponding to the biological potential only in Gelu variety (14.02), and in 2013, in both varieties, including the control variety - Aromat de Iași.

Acknowledgments. This paper was published under the frame of the European Social Fund, Human Resources Development Operational Programme 2007-2013, projectno. POSDRU/159/1.5/S/132765.

\section{REFERENCES}

1. Becker N, Martine JM, Vidal P (1992). La sècheresse. Interactions genotypes milieux: résultats de l'enquête "cépages" européens. Progrès Agricole et viticole, 22: (11-15)

2. Colibaba C, Cotea VV, Rotaru L, Tudose Sandu Ville S (2013). Studies of the Influence of Climatic Changes 
on Some Grape Varieties for White Wines in Moldavian Vineyards. Scientific Works, University of Agricultural Sciences and Veterinary Medicine of Iași, Horticulture Series 56(1): 275-278

3. Damian D, Savin C, Zaldea G, Măntăluță A, Alexandru C (2013). Studies on the Adaptability of Local Genotypes Vine to Climate Change in Copou-IaşiVineyard Ecosystem, Scientific Works, University of Agricultural Sciences and Veterinary Medicineof Iaşi, Horticulture Series 56(2):275280

4. Damian D, Calistru G, Crăcană Al, Rotariu C (1995) Genetic Behaviour of Certain Vine Varieties with high Resistance to Diseases to Stressful Environmental Factors. Scientific Works, University of Agricultural Sciences and Veterinary Medicinof Iaşi, Horticulture Series 38(1): 214220

5. Donici A, Simion C, Enache V (2013). Research on the Behaviourof Some Varieties of Vines in the Vineyard Area of Dealu Bujorului. Scientific Works, University of Agricultural Sciences and Veterinary Medicine of Iaşi, Horticulture Series 56(1):285 - 290
6. Haras D, Rotaru L (2012). The Behavior of Some Grapevine Varieties for White Wines Regarding Frost Resistance on 2011/2012 Winter in Iași and Cotnari Vineyards. Scientific Works, University of Agricultural Sciences and Veterinary Medicine of Iași, Horticulture Series 55(2):303-306

7. Maccarone G, Scienza A (1996). Valutzione dell'equilibrio vegeto-produttivo delle vite (Evaluation of the Vegetative-Productive Balance of Vine). L'informatore Agrario, 52:61-64

8. Reynier A (2000). Manuel de viticulture. $8^{\mathrm{eme}}$ édition. Ed. Tech \& Doc., Paris

9. Rotaru L, Colibaba C (2013). Phenological Changes in Some Grape Varieties for White Wines in the NorthEast Area of Moldova. Scientific Works, University of Agricultural Sciences and Veterinary Medicine of Iaşi, Horticulture Series 56(1):307-312

10. Vaudour E (2003). Approche écophysiologique à la parcelle. Les terroirs viticoles. Ed. Dunod, Paris 